\title{
Canopy temperature variability in a tropical rainforest, subtropical evergreen forest, and savanna forest in Southwest China
}

\author{
Qing-Hai Song ${ }^{(1-2)}$, \\ Yi-Ping Zhang ${ }^{(1-2-4)}$, \\ Li-Qing Sha ${ }^{(1-2)}$, \\ Xiao-Bao Deng ${ }^{(1-3)}$, \\ Yun Deng ${ }^{(1-3-6)}$, \\ Chuan-Sheng Wu ${ }^{(1-2-4)}$, \\ Zhi-Yun Lu ${ }^{(1-4)}$, \\ Ai-Guo Chen ${ }^{(1-5)}$, \\ Shu-Bin Zhang ${ }^{(1-5)}$, \\ Pei-Guang Li ${ }^{(1-5)}$, \\ Wen-Jun Zhou (1-2), \\ Yun-Tong Liu ${ }^{(1-2)}$
}

\section{Introduction}

Plant canopy temperature $(\mathrm{Tc})$ is a major driving factor in surface energy fluxes and provides insight into overall plant water status (Blonquist et al. 2009). Tc measurements with infrared thermometry have been widely used to manage deficit irrigation of field crops. For example, Tc depression has been shown to be significantly related to stomatal conductance across varieties of rice (Takai et al. 2010). Also, 12 infrared temperature sensors were installed in a mature peach orchard, which received different irrigation treatments (Wang \& Gartung 2010). However, few studies have used infrared methods to measure Tc in natural forests. One exception is Leuzinger \& Körner (2007), who il-

\begin{abstract}
Canopy temperature (Tc) measurements with infrared thermometry have been widely used to assess plant water status. Here, we evaluated Tc and its controlling factors in a primary tropical rainforest (TRF), subtropical evergreen broad-leaved forest (STF) and valley savanna forest (SAF) in southwestern China. We found differences between Tc and air temperature ( $\mathrm{Ta}$ ) of as much as $2.2{ }^{\circ} \mathrm{C}$ between the dry and wet seasons in the TRF. However, the canopyto-air temperature difference (Tc-Ta) was only $0.3{ }^{\circ} \mathrm{C}$ between the dry and wet seasons in the STF. Solar radiation (SR) was the dominant factor in Tc-Ta variations during the dry and wet seasons at the three sites. The increased heating in the canopy leaves was likely the result of low stomatal conductance leading to low transpiration cooling. Changes in Tc-Ta in the TRF were highly sensitive to the degree of stomatal closure. The change in Tc-Ta was controlled by the climate, but inherent plant traits, such as stomatal conductance, also played an important controlling role.
\end{abstract}

Keywords: Canopy Temperature, Drought Stress, Microclimate, Transpiration, Leaf Energy Balance

lustrated the importance of tree species composition for the local climate through assessments of canopy leaf temperature distribution over space and time for a mixed deciduous forest in NW Switzerland. Canopy architecture has a consistent influence on canopy foliage temperature in diverse, mixed deciduous forests: "dense canopy" species are warmer than "open canopy" species (Scherrer et al. 2011). Research has also shown that canopy foliage maintains a temperature close to Ta under normal conditions, but significantly warms up with ongoing drought (Scherrer et al. 2011). Another study demonstrated that Tc has great responsiveness to variations in water status of persimmon trees (Ballester et al. 2013): the Tc response to water stress

(1) Key Laboratory of Tropical Forest Ecology, Xishuangbanna Tropical Botanical Garden, Chinese Academy of Sciences, Menglun 666303 (China); (2) Global Change Ecology Group, Xishuangbanna Tropical Botanical Garden, Chinese Academy of Sciences, Menglun 666303 (China); (3) Xishuangbanna Station for Tropical Rain Forest Ecosystem Studies, Menglun 666303 (China); (4) Ailaoshan Station for Subtropical Forest Ecosystem Studies, Jingdong 676209 (China); (5) Yuanjiang Savanna Ecosystem Research Station, Xishuangbanna Tropical Botanical Garden, Chinese Academy of Sciences, Yuanjiang (China); (6) University of Chinese Academy of Sciences, Beijing 100049 (China)

@ Qing-Hai Song (sqh@xtbg.ac.cn)

Received: Sep 21, 2016 - Accepted: Mar 26, 2017

Citation: Song Q-H, Zhang Y-P, Sha L-Q, Deng X-B, Deng Y, Wu C-S, Lu Z-Y, Chen A-G, Zhang SB, Li P-G, Zhou W-J, Liu Y-T (2017). Canopy temperature variability in a tropical rainforest, subtropical evergreen forest, and savanna forest in Southwest China. iForest 10: 611-617. doi: 10.3832/ifor2223-010 [online 2017-05-17]

Communicated by: Silvano Fares

was different for each experimental season. In a year with normal water availability (2009), Tc did not allow detection of the existing differences in plant water status, but during a drought year (2011), water stressed trees had significantly higher Tc than control trees with differences of up to $1.7^{\circ} \mathrm{C}$ (Ballester et al. 2013).

IPCC-AR4 climate projections anticipated that climate change will increase temperatures, create greater variability in rainfall (both seasonal and annual), and generate more frequent and intense drought events worldwide (IPCC 2007). The higher air temperatures in combination with higher atmospheric vapor pressure deficits $\left(\delta_{\mathrm{e}}\right)$ will lead to higher transpiration demand. However, under drought stress conditions, water uptake rates cannot match the transpiration demands and leaf stomata close to maintain plant water balance, which in turn leads to higher leaf temperatures (Campbell \& Norman 1990, Jones 1999). Overall, different plant species in different vegetation communities are highly variable in functional traits, canopy architecture, rooting depth, and micrometeorological environment. The different responses of plant species to the expected climate changes might also be highly variable. There are still many uncertainties in relation to changes in Tc due to drought stress.

Primary tropical rainforests (TRFs), subtropical evergreen broad-leaved forests (STFs), and savanna forests (SAFs) are among the most important biomes in Southwest China because of their high primary productivity and unique characteristics (Tan et al. 2011). This area is exposed to Asian monsoon regimes from the south- 


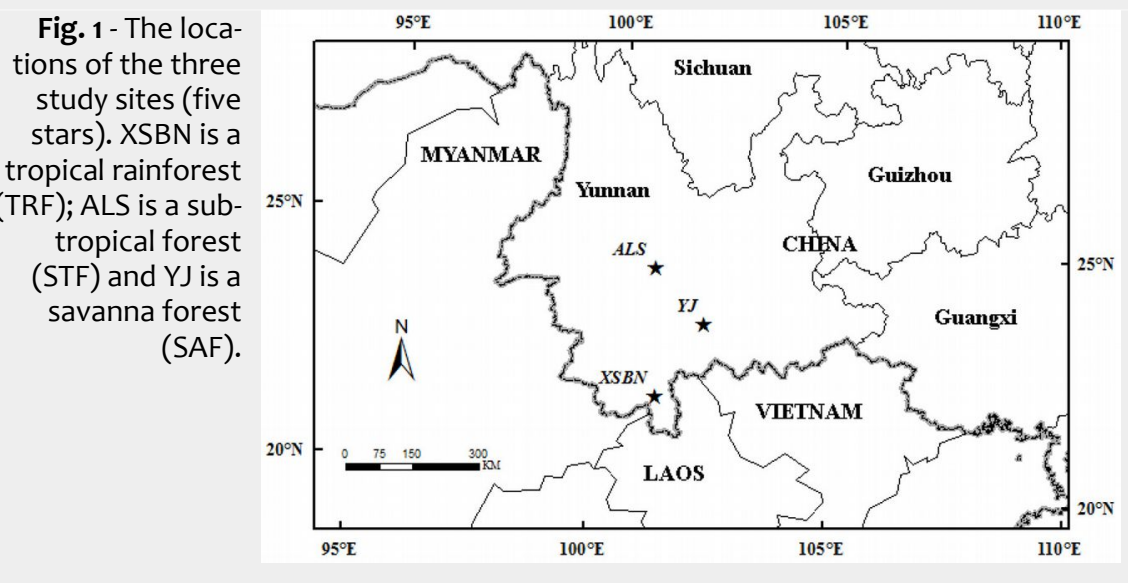

west (Indian Ocean) and from the southeast (Pacific Ocean). Due to the predominant effect of the two monsoons, the climate in the study region is strongly seasonal with a wet season from May to October, and a dry season from November to April (You et al. 2013).

From late 2009 through 2010, southwestern China experienced the most severe drought since 1959, providing a unique opportunity to directly evaluate how Tc changed with drought stress in the different forest ecosystems. We know that components of the canopy energy balance, such as solar radiation (SR), wind speed (Ws), Ta, and air relative humidity (RH), affect Tc (Jones 1992). The relative impact of each factor on Tc is likely to be different in different seasons and communities. However, little is known about Tc and its controlling factors in the TRF, STF, and SAF. Detailed studies of Tc are needed in these primary forests to improve our understanding of their potential sensitivity to drought stress.

The objectives of this study were to: (1) quantify the magnitude and seasonal dynamics of Tc and the relative contribution of different factors to $\mathrm{Tc}$ in the three forest ecosystems, and (2) evaluate the differences in Tc during normal and drought years.

\section{Methods}

\section{Site information}

Three typical primary forests (TRF, STF, ang et Y.T. Chang, and Lithocarpus xylocar-

Tab. 1 - Site information. (MAT): Mean annual temperature $\left({ }^{\circ} \mathrm{C}\right)$.

\begin{tabular}{lccc}
\hline Site & TRF & STF & SAF \\
\hline Location & $21^{\circ} 55^{\prime} 39^{\prime \prime} \mathrm{N}$ & $24^{\circ} 32^{\prime} 17^{\prime \prime} \mathrm{N}$ & $23^{\circ} 28^{\prime} 40^{\prime \prime} \mathrm{N}$ \\
& $101^{\circ} 15^{\prime} 55^{\prime \prime} \mathrm{E}$ & $101^{\circ} 01^{\prime} 10^{\prime \prime} \mathrm{E}$ & $102^{\circ} 10^{\prime} 56^{\prime \prime} \mathrm{E}$ \\
Elevation & 780 & 2502 & 481 \\
MAT $\left({ }^{\circ} \mathrm{C}\right)$ & 22 & 11 & 24 \\
Rainfall (mm year ${ }^{-1}$ ) & 1487 & 1931 & 802 \\
Predominant & Pometia tomentosa, & Machilus bombycina, & Machilus \\
species & Gironniera subaequalis & Lithocarpus chintungensis & bombycina \\
Canopy height (m) & 33 & 26 & 5 \\
Soil type & loamy Lateritic Oxisol & loamy Alfisol & ferralic Cambisol \\
Observation period & $2009-2014$ & $2009-2014$ & 2014 \\
\hline
\end{tabular}

pus. The soils are loamy Alfisols, and the 3-7 $\mathrm{cm}$ organic carbon horizon had a $\mathrm{pH}$ of 4.5 .

\section{Savanna forest (SAF)}

The SAF site was located in the Yuan $\mathrm{Ri}$ ver region. The dry climate is due to the strong evapotranspiration in combination with a pronounced 6-month dry season (November-April). Vegetation is dominated by deciduous shrub species. The soil is a ferralic cambisol, containing moderate organic matter, higher $\mathrm{N}, \mathrm{P}, \mathrm{K}, \mathrm{Ca}$, and $\mathrm{Mg}$ concentrations, lower cation exchange capacity and moderate $\mathrm{pH}$ value, compared to soils of other tropical savannas

The key information of the three sites is shown in Tab. 1 and Fig. S1 (Supplementary material).

\section{Tc and meteorological factors}

An infrared temperature sensor (Apogee Instruments Inc., Logan, UT, USA) was installed at each site to measure Tc. The sensors were installed on observational towers (Fig. 2) mounted on 4-cm diameter galvanized metal pipes $3 \mathrm{~m}$ above each forest canopy surface. The sensor was aimed at the canopy, with view half angles of approximately $22^{\circ}$ from nadir. The absolute accuracy of the sensor is $\pm 0.2^{\circ} \mathrm{C}$. The radiation detected by an infrared radiometer included two components: (i) radiation directly emitted by the target surface; and (ii) radiation reflected from the background. The second component is often neglected. The magnitude of the two components in the radiation detected by the radiometer was estimated using the emissivity and reflectivity of the target surface (Blonquist et al. 2009).

Instruments for measuring $\mathrm{Ta}$ and $\mathrm{RH}$ (HMP $45 \mathrm{C}^{\oplus}$, Vaisala, Helsinki, Finland) and wind speed $\left(A 100 R^{\oplus}\right.$, Vector Instruments, Denhighshire, UK) were installed at the same height at each site. Radiation sensors for downward and upward, short and longwave radiation (CNR-1/CM11 ${ }^{\circledR}$, Kipp \& Zonen, Delft, the Netherlands) were installed on a horizontal pole $3 \mathrm{~m}$ away from the tower at each site. Profiles of soil moisture were measured at different depths (105T/ $107 \mathrm{~L}^{\oplus}$, Campbell Scientific Inc., Logan, UT, USA) at each site. All of the meteorological data were collected by a CR1000 ${ }^{\circledast}$ device (Campbell Scientific Inc.) every $30 \mathrm{~min}$ at each site.

\section{Sap flow measurement}

Measurements of sap flow were made using thermal dissipation probes (Model TDP-30 ${ }^{\circledR}$, Dynamax Inc., Houston, TX, USA). Each probe (30 mm in length and $1.3 \mathrm{~mm}$ in diameter) was inserted $30 \mathrm{~mm}$ into the sapwood of a sample tree bole at the TRF and STF sites, respectively. All probes were shielded with aluminum foil to minimize temperature fluctuations and avoid direct solar heating in the sapwood, following the procedures described by Wilson et al. (2001). Sap flow data were collected every minute and were stored on the data logger 
(Dynamax Inc.). Mean sap flow density ( $\mathrm{g}$ $\mathrm{H}_{2} \mathrm{O} \mathrm{m}^{-2} \mathrm{~s}^{-1}$ ) for the sample tree was calculated using the methods of Granier (1987).

\section{Canopy leaf stomatal conductance} measurements

In the wet season, we measured leaf stomatal conductance $\left(\mathrm{g}_{c}\right)$ using a portable photosynthetic system (LI-6400 ${ }^{\circledR}$, LI-COR, Lincoln, NE, USA) at the TRF and STF sites, respectively. For each species, 3-12 sunexposed, fully-developed mature leaves from different individuals were selected for stomatal conductance measurements. Measurements were carried out on sunny days between 09:30 and 11:30 a.m.

\section{Leaf energy balance function}

We used the leaf energy balance function (Jones 1992, Maes et al. 2011, Maes \& Steppe 2012) to investigate the possible effects that climate change may have on the canopy-to-air temperature difference (TcTa - eqn. 1):

$$
T c-T a=\frac{r_{a H} r_{V} \gamma R_{n}-r_{a H} \rho_{a} C_{p} \delta_{e}}{\rho_{a} C_{p}\left(\gamma r_{V}+\Delta r_{a H}\right)}
$$

where $\rho_{\mathrm{a}}$ is the air density $\left(\mathrm{kg} \mathrm{m}^{-3}\right), C_{\mathrm{p}}$ is the specific heat of air at constant pressure $(J$ $\left.\mathrm{kg}^{-1} \mathrm{~K}^{-1}\right), r_{\mathrm{aH}}$ is the boundary layer resistance to heat $\left(\mathrm{s} \mathrm{m}^{-1}\right), \gamma$ is the psychrometer constant $\left(\mathrm{Pa} \mathrm{K}^{-1}\right), R_{\mathrm{n}}$ is net radiation $\left(\mathrm{W} \mathrm{m}^{-2}\right), \delta_{\mathrm{e}}$ is the vapour pressure deficit $(\mathrm{kPa}), \Delta r_{\mathrm{aH}}$ is the slope of the linearized relationship between Tc-Ta and the vapour pressure deficit of air, and $r_{\mathrm{V}}$ is the total resistance to latent heat transport $\left(\mathrm{s} \mathrm{m}^{-1}\right)$.

\section{Results}

\section{Meteorological conditions}

Fig. 2 shows average values of SR, Ta, RH, and Ws from 11:00-15:00 $\mathrm{h}$ for each day of measurements in the three forests. The values of SR for the whole year were scattered and there were no significant differences between the three forests (Fig. 2a). In general, Ta was highest in the SAF throughout the year and was lowest in the STF (Fig. 2b). In particular, Ta in late dry season in the SAF was almost $20^{\circ} \mathrm{C}$ higher than in the STF. RH showed contrary pat-

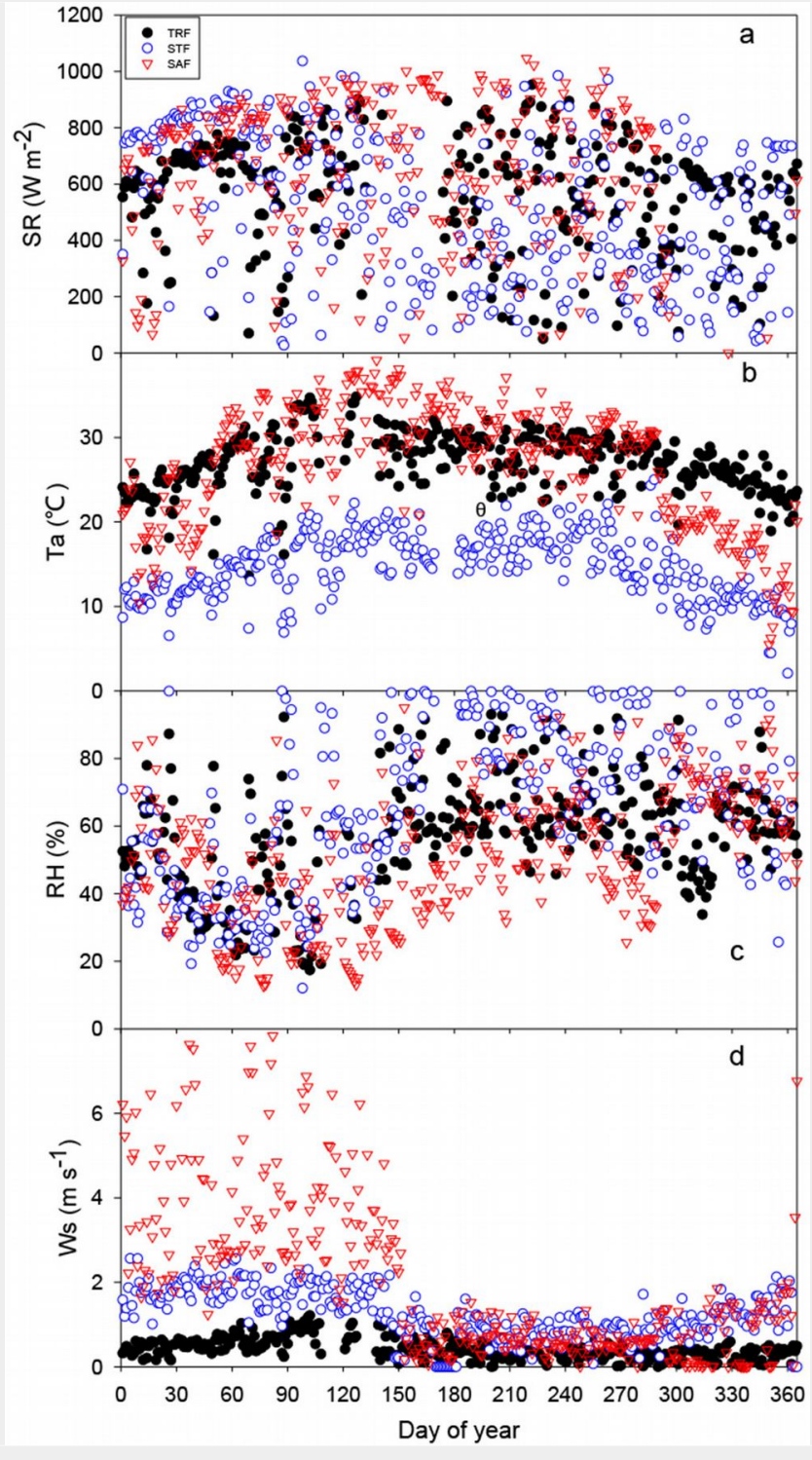

Fig. 2 - Time series of daily micrometeorological variables for the TRF, STF and SAF sites: (a): shortwave incoming radiation (SR), (b): air temperature (Ta), (c): relative humidity $(\mathrm{RH})$, and wind speed (Ws). (TRF): tropical rainforest site; (STF): subtropical evergreen forest site; (SAF): savanna forest site.

terns (Fig. 2C), and low Ws conditions per- the maximum Tc-Ta value occurred at 14:00 sisted throughout the whole wet season in h (Fig. 3a). The maximum Tc-Ta values in the three forests (Fig. 2d).

\section{Seasonal patterns of canopy} temperature (TC)

In the TRF, the daily peak of the Tc-Ta appeared to occur at approximately 12:00 $\mathrm{h}$ in the dry season, while in the wet season, the dry and wet season in the TRF were 2.0 and $-0.2{ }^{\circ} \mathrm{C}$, respectively. In the STF, the daily peak values of Tc-Ta in the dry and wet season also appeared to occur around 11:30 h (Fig. 3b), while the maximum Tc-Ta value in the wet season occurred at 13:00 h. The difference of the maximum Tc-Ta
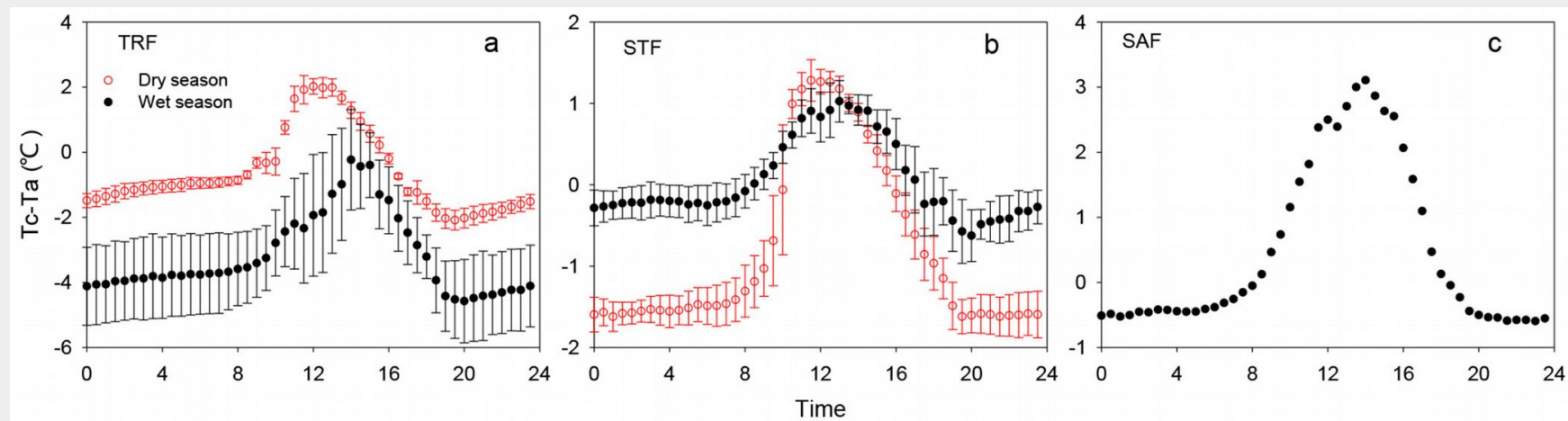

Fig. 3 - Mean diurnal time series of air to canopy temperature difference during dry and wet season at the TRF, STF and SAF sites. (TRF): tropical rainforest site; (STF): subtropical evergreen forest site; (SAF): savanna forest site. 
Tab. 2 - Coefficients (B) and relative contributions ( $\beta \%$ ) to Tc-Ta of the analyzed environmental factors. (TRF): tropical rainforest site; (STF): subtropical evergreen forest site; (SAF): savanna forest site. (**): $p<0.01 ;\left(^{*}\right)$ : $p<0.05$ (t-test).

\begin{tabular}{|c|c|c|c|c|c|c|c|c|c|c|c|c|}
\hline \multirow{3}{*}{ 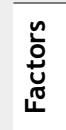 } & \multicolumn{6}{|c|}{ Dry season } & \multicolumn{6}{|c|}{ Wet season } \\
\hline & \multicolumn{2}{|l|}{ TRF } & \multicolumn{2}{|l|}{ STF } & \multicolumn{2}{|l|}{ SAF } & \multicolumn{2}{|l|}{ TRF } & STF & \multicolumn{3}{|c|}{ SAF } \\
\hline & B & $\beta \%$ & B & $\beta \%$ & B & $\beta \%$ & B & $\beta \%$ & B & $\beta \%$ & B & $\boldsymbol{\beta} \%$ \\
\hline SR & 0.003 & 39 & 0.003 & $49^{* *}$ & - & - & 0.009 & $43^{* *}$ & 0.003 & $55^{* *}$ & 0.004 & $54^{* *}$ \\
\hline $\mathrm{Ta}$ & -0.073 & 23 & -0.119 & $31^{*}$ & - & - & -0.351 & $19^{*}$ & -0.053 & 10 & 0.074 & 14 \\
\hline $\mathrm{RH}$ & -0.021 & 25 & -0.004 & 6 & - & - & -0.069 & 17 & -0.021 & 19 & -0.035 & 30 \\
\hline Ws & 0.896 & 13 & -0.51 & $14^{*}$ & - & - & -4.911 & $21^{* *}$ & -0.743 & $16^{*}$ & -0.079 & 2 \\
\hline
\end{tabular}

value between the dry and wet season in the STF was small and the maximum values of the dry and wet season were $1.3{ }^{\circ} \mathrm{C}$ and $1.0{ }^{\circ} \mathrm{C}$, respectively. In the SAF, the maximum TC-Ta value was about $3.1{ }^{\circ} \mathrm{C}$ at $14: 00 \mathrm{~h}$ in the wet season (growing season - Fig. 3c).

To explore more deeply the influence of microclimate factors on Tc-Ta under the varying climatic conditions, we evaluated the correlations of environmental conditions with Tc-Ta on a statistical basis during the dry and wet seasons. Season-specific

multivariable correlations between Tc-Ta and microclimate conditions are shown in Tab. 2. The analysis revealed the relative contribution of each parameter to Tc-Ta. SR is one of the primary factors correlated with Tc-Ta during the dry and wet seasons in the three sites. During the dry season, there was no single important variable in the TRF, but SR was still the most influential $(\beta \%=39 \%)$. The relative contribution of $\mathrm{Ta}$ and $\mathrm{RH}$ were almost equivalent at the TRF site. The two climate variables, SR and Ta, accounted for $80 \%$ of the variations in

Fig. 4 - Mean diurnal time series of

$\mathrm{SR}, \mathrm{Ta}, \mathrm{RH}$, and Ws on September 2009 and 2010 at TRF and STF sites. (TRF): tropical rainforest site; (STF): subtropical evergreen forest site.
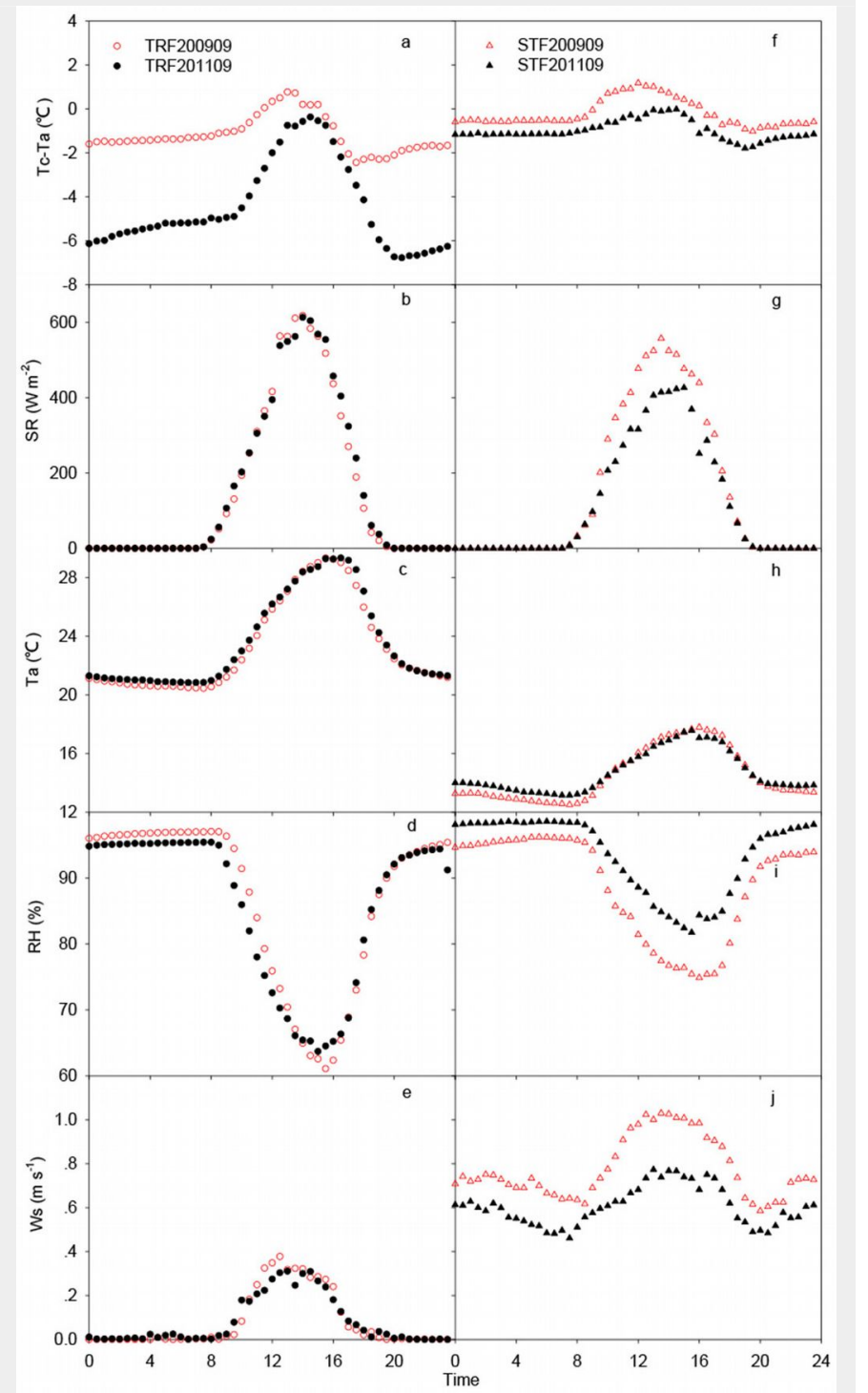

Tc-Ta in the STF during the dry season. During the wet season, Ws was the second most significant variable $(\beta \%=21 \%)$ at the TRF site. Ws also influenced Tc-Ta significantly at the STF site during the wet season, while $\mathrm{Ta}$ and $\mathrm{RH}$ were not significant. $\mathrm{RH}$ accounted for $30 \%$ of the variations in TC-Ta at the TRF site but was non-significant at the SAF site.

\section{Interannual dynamics of Tc}

Rainfall has decreased since the wet season of 2009, and the reduced rainfall continued until the end of the dry season in 2010 for the entire region (Tan et al. 2015). Therefore, we selected the middle of the wet season (September) in a drought year (2009) and a normal year (2011) to evaluate how Tc changes with drought stress at the TRF and STF sites.

The daily peak values of Tc-Ta among the normal and drought years at both sites appeared to occur at approximately 13:0014:00 h, which was consistent with the period of maximum daily solar radiation but before the period in which Ta reached the daily maximum (Fig. 4a). There was virtually no difference in Tc-Ta values during the night when there was no solar heating. TcTa values in the drought year (2009) were higher than in the normal year (2011) for both sites. The maximum Tc-Ta values for the drought year and normal year were $0.78{ }^{\circ} \mathrm{C}$ and $-0.36{ }^{\circ} \mathrm{C}$ in the TRF; and $1.18^{\circ} \mathrm{C}$ and $-0.01{ }^{\circ} \mathrm{C}$ in the STF, respectively. Thus, the difference of Tc-Ta between the drought and normal years in both sites was about $1.1^{\circ} \mathrm{C}$.

Similarly, we also analyzed the relative contribution of each parameter to daylight (10:00-17:00 h) Tc-Ta during the drought and normal years at both sites. In the TRF, SR and Ws affected Tc-Ta both in drought and normal years. The relative contribution of SR in the normal year (2011) was higher than that in the drought year (2009, $\beta \%=$ $19 \%$ - Tab. 3). The relative contribution ( $\beta \%$ $=32 \%$ ) of Ws in the normal year (2011) was also higher than that in the drought year $(2009, \beta \%=10 \%)$ in the TRF. In contrast, the $\mathrm{RH}$ contribution in the drought year $(\beta \%=$ $30 \%$ ) was twice as much as that in the normal year ( $\beta \%=15 \%$ - Tab. 3$)$.

In the STF, SR also affected Tc-Ta in both years significantly. The relative contribution $(\beta \%=32 \%)$ of SR in the drought year (2009) was higher than that in normal year (2011, $\beta \%=23 \%-$ Tab. 3$)$.

\section{Tc-Ta variations in a changing climate}

Based on the results described above, we collected data for the standard meteorological conditions at the three sites. For $g_{c}$ of the sample tree species at the SAF site, we used the $g_{c}$ values from the literature (Zhang et al. 2007) for the same site.

Increasing drought frequency has the potential to affect the carbon and water cycle in forest ecosystems. Warmer global temperatures are expected to cause an intensification of the hydrologic cycle, with 
increased evaporative demand for ecosystems. As mentioned above, plants under drought stress decrease stomatal conductance, thereby reducing transpiration and increasing Tc. Therefore, we assumed a decrease to $25 \%, 50 \%$, and $75 \%$ of maximum $\mathrm{g}_{c}$ values at the three sites in our examination of the differences in Tc between the three forest ecosystems in a changing climate.

Tc-Ta was very sensitive to all simulated meteorological conditions (Fig. 5). Tc-Ta increased linearly with increasing SR and RH. Tc-Ta also decreased non-linearly with increasing Ta and Ws (Fig. 5). Our simulation results were consistent with the research by Maes et al. (2011) and Maes \& Steppe (2012). Tc-Ta increased sharply with $\mathrm{SR}$ at all $g_{c}$ levels and sites. At the same level of $g_{c}, T c-T a$ had a steeper increase with increasing SR in the STF than the other two sites (Fig. 5a-c), on average, approximately $2{ }^{\circ} \mathrm{C}$ higher than the other two sites. However, the difference of Tc-Ta at three $g_{c}$ levels with increasing SR in the STF was smallest, indicating that the change in Tc-Ta was relatively insensitive to the degree of stomatal closure. In contrast, the difference in Tc-Ta at the three $g_{c}$ levels in the TRF became larger with increasing SR. In the TRF, the standard Ta was higher than at STF, while RH in the TRF was lower than in the STF, suggesting that standard $\delta_{\mathrm{e}}$ in the TRF was higher than in the STF. Therefore, evaporative demand was significantly higher in the TRF than in the STF. Additionally, TRF had the highest $g_{c}$ of the three sites, indicating that $g_{c}$ could still maintain relatively high absolute values even with partial stomatal closure in the TRF. Consequently, canopy transpiration in the TRF corresponding to higher $g_{c}$ was relatively higher than in the STF (Zhang et al. 2013, 2014), leading to high canopy transpirative cooling (lower $\mathrm{Tc}-\mathrm{Ta}$ ) at the same level of SR (Fig. 5a).

Tc-Ta showed significant opposite patterns with increasing Ta and RH (Fig. $5 \mathrm{~d}-\mathrm{i}$ ), indicating that Tc-Ta decreased with in-

Tab. 3 - The coefficients (B) and relative contributions ( $8 \%$ ) of environmental factors are presented for each variable. (TRF): tropical rainforest site; (STF): subtropical evergreen forest site; (SAF): savanna forest site. $\left({ }^{* *}\right): p<0.01 ;\left(^{*}\right): p<0.05$ (t-test).

\begin{tabular}{lcccccccc}
\hline & \multicolumn{1}{l}{ TRF } & \multicolumn{7}{c}{ STF } \\
\cline { 2 - 9 } Factors & $\mathbf{2 0 0 9}$ & & $\mathbf{2 0 1 1}$ & \multicolumn{2}{c}{ 2009 } & \multicolumn{2}{c}{$\mathbf{2 0 1 1}$} \\
\cline { 2 - 9 } & B & B\% & B & B\% & B & B\% & B & B\% \\
\hline SR & 0.004 & $19^{* *}$ & 0.004 & $32^{* *}$ & 0.004 & $32^{* *}$ & 0.005 & $23^{* *}$ \\
Ta & -0.652 & 41 & 0.202 & 24 & -0.611 & 47 & -0.984 & 42 \\
RH & -0.113 & 30 & -0.035 & 15 & -0.043 & 13 & -0.202 & 33 \\
Ws & 2.744 & $10^{*}$ & 5.745 & $29^{*}$ & 1.477 & 8 & -0.790 & 2 \\
\hline
\end{tabular}

creasing $\delta_{\mathrm{e}}$. Similarly, the difference of TcTa at three $g_{c}$ levels with increasing Ta or $\delta_{\mathrm{e}}$ in the STF site was small while the differences were large in the TRF and SAF. In the STF, Tc-Ta decreased slightly with increasing Ta or VPD, indicating that Tc-Ta did not particularly depend on Ta or $\delta_{\mathrm{e}}$ at low gc levels (Fig. 5e). In contrast, Tc-Ta was highly sensitive to the increasing Ta or VPD in the TRF, due to relatively more open stomata and higher canopy transpiration.

Overall, Tc in the three forests responded very differently to the climate change. The change in Tc-Ta was controlled by the climate, but plant inherent traits, such as stomatal conductance, also played an important controlling role.

\section{Discussion}

\section{Seasonal variations in Tc-Ta}

Tc-Ta in the different seasons exhibited distinct diurnal cycles at the three sites. Our study showed Tc-Ta differences of as much as $2.2{ }^{\circ} \mathrm{C}$ between the dry season and the wet season in the TRF. However, Tc-Ta differences were only $0.3{ }^{\circ} \mathrm{C}$ between the dry and the wet season in the STF. A combined analysis of the four controlling variables (SR, Ta, RH, and Ws) across the three sites indicated a clear distinction between the dry and wet season with respect to the control Tc-Ta. SR was the dominant factor in Tc-Ta variations during the dry and wet seasons at the three sites (Tab. 2). This clearly indicated that the input of radiation energy mostly drives Tc-Ta, a result that was also found by Maes et al. (2011). All the effects of the micrometeorological factors were variable among the seasons and sites, which means that focusing on seasons was critical to better understand Tc patterns (Wang \& Gartung 2010). This highlights the importance of large seasonal variability in the Asian monsoon region, which leads to a shift in the dominant factors between seasons.

Plants under soil water deficit decrease stomatal conductance, thereby reducing transpiration and increasing leaf temperature. At TRF and STF sites, measurements conducted with sap flow methods showed that canopy transpiration for dominant tree species in the dry season were lower than in the wet season at both sites (Fig. S2 in Supplementary material). The reduction in transpiration in the dominant canopy trees during the dry season (with high evaporative demand) could partly explain the increase in Ta differences of the canopy (Fig. 3).

\section{Interannual variations in Tc-Ta}

Tc-Ta variations do correspond with variations in SR, Ta, RH, and Ws in the different seasons. Hence, it is important to keep in mind that variations in Tc-Ta in the dry and wet season at the same site do not neces-

Fig. 5 - Influence of climate conditions on (Tc-Ta), including: shortwave incoming radiation (SR), air temperature $(\mathrm{Ta})$, vapor pressure deficit (VPD), and wind speed (Ws), for three levels of $g_{c}$ at the rubber plantation (a, c, e, g) and the tropical rainforest sites $(b, d, f, h)$.
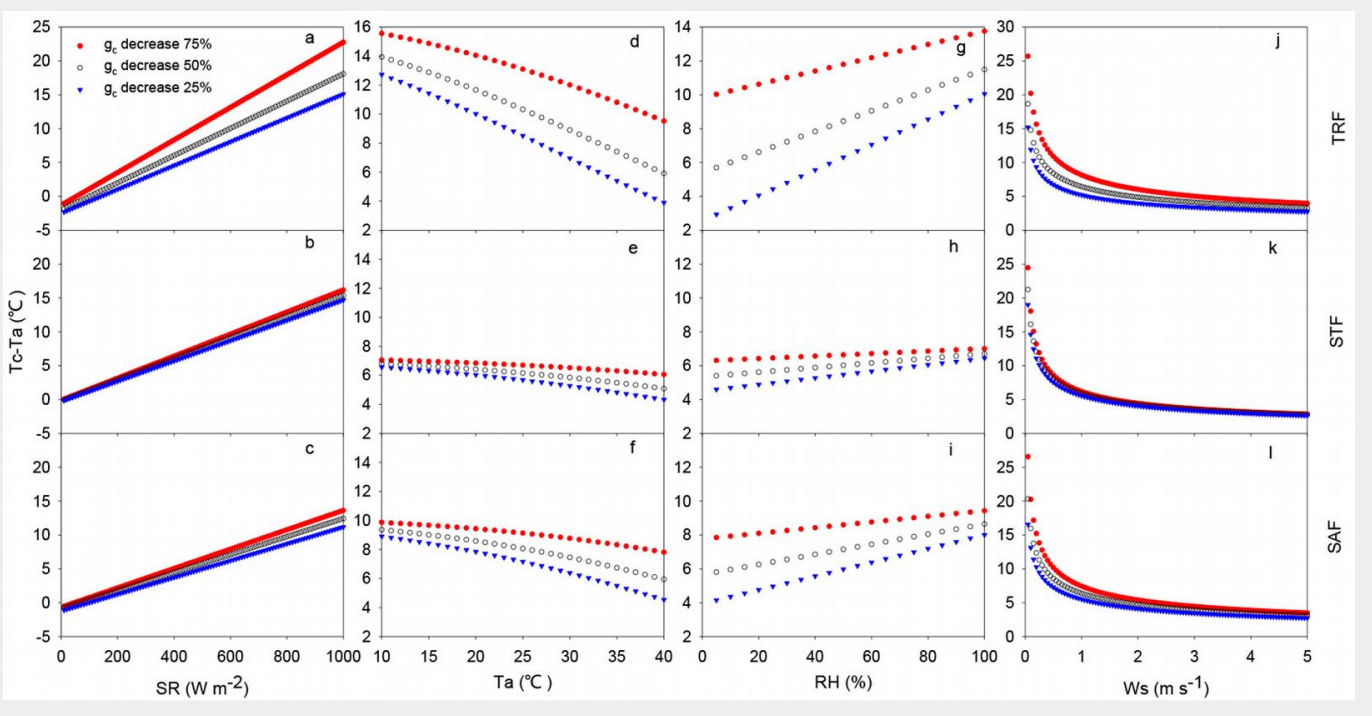
sarily result solely from soil water availability. Tc-Ta variations can also be an indication of the relative changes in plant tran spiration under similar micrometeorological conditions at the same site. To ensure that the changes in Tc-Ta were connected to changes in transpiration, we selected the same period (September) in 2009 and 2011.

In the TRF, there was no significant difference between all of the micrometeorological conditions in September during the drought (2009) and the normal year (2010) mean values in the TRF (paired t-test: $p$ 0.07 - Fig. 4b-d), indicating that micrometeorological conditions were similar during the study period in 2009 and 2011. Tc-Ta at noon in 2009 was higher by about $1{ }^{\circ} \mathrm{C}$ than that in 2011. The increased heating in the canopy leaves in 2009 was likely the result of low stomatal conductance, leading to low transpiration cooling. During sunny days, canopy transpiration was the main contribution to evapotranspiration (latent heat flux), because soil and canopy evaporation were exceptionally low in days with out rainfall. The mean latent heat flux values in September in 2009 and 2011 in the TRF were $179 \mathrm{~W} \mathrm{~m}^{-2}$ and $212 \mathrm{~W} \mathrm{~m}^{-2}$, respec tively. Therefore, the latent heat flux data by eddy covariance method proved that the higher Tc-Ta in 2009 was due to a re duction in canopy transpiration, as the latent heat flux was lower than in 2011. Dur ing the drought period, trees saved soil water by increasing the surface resistance and reducing the transpiration rate, and for this reason, the canopy maximum temperature exceeded the optimum temperature. We observed a Tc-Ta of $0.78{ }^{\circ} \mathrm{C}$ for the drought year in the TRF, which was consis tent with the reported $0.6-0.8^{\circ} \mathrm{C}$ for a tem perate forest with "dense canopies" at the beginning of a drought period (Scherrer et al. 2011).

Wang \& Gartung (2010) found that the midday Tc-Ta in a water-stressed, deficit irrigation treatment of peach trees were in the range $5-7{ }^{\circ} \mathrm{C}$. The maximum Tc difference between deficit-irrigated and control trees observed in persimmon trees was 4 ${ }^{\circ} \mathrm{C}$ (Ballester et al. 2013), while the maximum Tc difference between drought year and normal year was about $1{ }^{\circ} \mathrm{C}$ in the TRF. The possible reasons for the lower Tc-Ta found in the tropical rain forest include: (i) tree species in the tropical rain forest are highly diversified in canopy architecture. The temperature of the branches and selfshaded leaves were not measured, result ing in an underestimation of the actual Tc. This might be a general problem in natural forests (Scherrer et al. 2011). (ii) Most stud ies dealing with drought effects on Tc on crops have worked with precise irrigation treatments for determining the Tc to the difference in drought stress level, such as irrigated $50 \%$ evapotranspiration and irrigated 25-33\% (Campbell \& Norman 1990, Wang \& Gartung 2010, Ballester et al. 2013). Therefore, the Tc of crops might be more sensitive to severe drought stress in the irrigation treatments.

To evaluate the effect of drought stress on soil water, we analyzed the water content in the soil profile at both sites (Fig. S3 in Supplementary material). We found that although the total rainfall in 2009 was 30\% lower compared with the average value for the past 50 years in this region (Song et al. 2013), deep soil moisture did not decrease significantly (Fig. S3b in Supplementary material). The dominant canopy tree species have deep roots and can use deep soil water (Kume et al. 2007). The deeper roots of the larger canopy dominant trees could be the reason for the lower impact of soil drought on Tc in larger trees, even in the drought environment. If there was not a sufficient amount of water in the entire soil profile for canopy cooling, Tc-Ta could be increased continually (Duffková 2006).

In the STF, the maximum difference in Tc between the drought year and normal year was also about $1{ }^{\circ} \mathrm{C}$. However, the micrometeorological conditions, such as $\mathrm{SR}, \mathrm{RH}$, and Ws, were different between the drought and normal year (Fig. 4g-j). Consequently, the Tc difference should correspond with variations in the micrometeorological conditions.

Overall, infrared Tc is a result of the energy balance, micrometeorological conditions, and plant-controlled transpiration. Measurement methods provide a tool for assessment and planning for water stress in the different seasons.

\section{Implications and uncertainties} regarding Tc measurements in forests Infrared Tc measurements provided a useful evaluation of plant response to environmental stress in different forest ecosystems. Infrared Tc measurements are automatic and effective, providing an alternative option to conventional methods such as stomatal conductance or stem water potential measurements in monitoring plant water status (Jackson 1991, Jones 1999, Wang \& Gartung 2010, Ballester et al. 2013).

However, monitoring Tc with an infrared temperature sensor in a fixed position only partially covers the canopy, and the data are too limited to account for variations in the entire canopy and differences between species, particularly for high diversity tropical and subtropical forests. For example, canopy architecture has a consistent influence on canopy foliage temperature, in that "dense canopy" species are warmer than "open canopy" species (Scherrer et al. 2011). In addition, the temperature of shaded leaves is lower than the sunlit leaves of the same trees (Ballester et al. 2013). The use of Tc measurements to detect plant water stress appears to be more precise in tree species with larger leaf sizes than species with smaller leaves (Ballester et al. 2013). Leaf adaptations of some species to drought, namely smaller leaf dimensions and more vertically oriented leaves, also result in lower Tc-Ta (Maes et al. 2011). Despite the fact that infrared Tc measurements can be used as a water stress indicator, there has yet to be a critical assessment of the relationship between Tc and plant species composition, canopy structure, and leaf functional traits.

\section{Conclusions}

The four meteorological controlling variables (SR, Ta, RH, and Ws) across the three sites indicated a clear distinction between the dry and wet season with respect to the control of Tc-Ta. SR was the dominant factor in TC-Ta variations during the dry and wet seasons in all three sites. Tc-Ta at noon in the drought year (2009) was about $1{ }^{\circ} \mathrm{C}$ higher than Tc-Ta in a normal year (2011) in the TRF. The increased heating of canopy leaves in the drought year (2009) was likely the result of low stomatal conductance leading to low transpiration cooling. Changes in Tc-Ta in the TRF were highly sensitive to the degree of stomatal closure, while changes in TC-Ta in the STF were relatively insensitive to the degree of stomatal closure. Changes in Tc-Ta were controlled by climate conditions, but plant inherent traits, such as stomatal conductance, also played important driving roles.

\section{Acknowledgements}

We thank Lei Yu, Meng-Nan Liu and Qi Luo for their assistance in the field. This work was supported by the Xishuangbanna Ecological Station for Tropical rain forest, the Ailaoshan Station for Subtropical Forest Ecosystem Research and the Yuanjiang Savanna Ecological station. This study was funded by the National Natural Science Foundation of China (41671209, U1602234, 41405143), the Yunnan Natural Science Foundation of Yunnan Province, China (2013FB077) and the National Key Research and Development Program of China (2016YFC0502105).

\section{References}

Ballester C, Jiménez-Bello MA, Castel JR, Intrigliolo DS (2013). Usefulness of thermography for plant water stress detection in citrus and persimmon trees. Agricultural and Forest Meteorology 168: 120-129. - doi: 10.1016/j.agrformet. 2012.08.005

Blonquist JM, Norman JM, Bugbee B (2009). Automated measurement of canopy stomatal conductance based on infrared temperature. Agricultural and Forest Meteorology 149: 21832197. - doi: 10.1016/j.agrformet.2009.06.021 Campbell GS, Norman JM (1990). Estimation of plant water status from canopy temperature: an analysis of the inverse problem. In: "Applications of Remote Sensing in Agriculture" (Steven MD, Clark JA eds). Butterworths, London, UK, pp. 255-271. - doi: 10.1016/B978-0-408-0476 7-8.50021-9

Duffková R (2006). Difference in canopy and air temperature as an indicator of grassland water stress. Soil and Water Research 4: 127-138. [online] URL: http://81.0.228.28/publicFiles/820 30.pdf 
Granier A (1987). Evaluation of transpiration in a Douglass-fir stand by means of sap flow measurements. Tree Physiology 3: 309-320. - doi: 10.1093/treephys/3.4.309

IPCC (2007). Climate Change 2007: Impacts, adaptation and vulnerability. Contribution of Working Group II to the Fourth Assessment Report of the IPCC (Parry ML, Canziani OF, Palutikof JP, Jvan P, Linden Hanson CE eds). Cambridge University Press, Cambridge, UK, pp. 976.

Jackson RD (1991). Relationship between normalized leaf water potential and crop water stress index values for acala cotton. Agriculture Water Management 20: 109-118. - doi: 10.1016/ 0378-3774(91)90010-G

Jones HG (1992). Plants and microclimate: a quantitative approach to environmental plant physiology. Cambridge University Press, Cambridge, UK, pp. 115-120. - doi: 10.1017/CBO9780 511845727

Jones HG (1999). Use of infrared thermometry for estimation of stomatal conductance as a possible aid to irrigation scheduling. Agricultural and Forest Meteorology 95: 139-149. - doi: 10.1016/S0168-1923(99)00030-1

Kume TH, Takizawa N, Yoshifuji K, Tanaka C, Tantasirin N, Tanak Suzuki M (2007). Impact of soil drought on sap flow and water status of evergreen trees in a tropical monsoon forest in northern Thailand. Forest Ecology and Management 238: 220-230. - doi: 10.1016/j.foreco.2006. 10.019

Leuzinger S, Körner C (2007). Tree species diversity affects canopy leaf temperatures in a mature temperate forest. Agricultural and Forest Meteorology 146 (1-2): 29-37. - doi: 10.1016/j.agr formet.2007.05.007

Maes WH, Achten WMJ, Reubens B, Muys B (2011). Monitoring stomatal conductance of Jatropha curcas seedlings under different levels of water shortage with infrared thermography. Agricultural and Forest Meteorology 151: 554-564. - doi: 10.1016/j.agrformet.2010.12.011 Maes WH, Steppe K (2012). Estimating evapo- transpiration and drought stress with groundbased thermal remote sensing in agriculture: a review. Journal of Experimental Botany 63: 4671-4712. - doi: 10.1093/jxb/ers165

Scherrer D, Karl-Friedrich BM, Christian K (2011). Drought-sensitivity ranking of deciduous tree species based on thermal imaging of forest canopies. Agricultural and Forest Meteorology 151: 1632-1640. - doi: 10.1016/j.agrformet.2011. 06.019

Song QH, Lin H, Zhang YP, Tan ZH, Zhao JF, Zhao JB, Zhang XL, Zhou WJ, Yu L, YangLY, Yu GR, Sun XM (2013). The effect of drought stress on self-organisation in a seasonal tropical rainforest. Ecological Modelling 265: 136-139. - doi: 10.1016/j.ecolmodel.2013.06.010

Takai T, Yano M, Yamamoto T (2010). Canopy temperature on clear and cloudy days can be used to estimate varietal differences in stomatal conductance in rice. Field Crops Research 115: 165-170. - doi: 10.1016/j.fcr.2009.10.019

Tan ZH, Zhang YP, Schaefer D, Yu GR, Liang N, Song $\mathrm{QH}$ (2011). An old-growth subtropical Asian evergreen forest as a large carbon sink. Atmospheric Environment 45 (8): 1548-1554. doi: 10.1016/j.atmosenv.2010.12.041

Tan ZH, Zhang YP, Deng XB, Song QH, Liu WJ, Deng Y, Tang JW, Liao ZY, Zhao JF, Song L, Yang LY (2015). Interannual and seasonal variability of water use efficiency in a tropical rainforest: tesults from a 9 year eddy flux time series. Journal of Geophysical Research: Atmosphere 120: 464-479. - doi: 10.1002/2014 JD022535

Wang D, Gartung J (2010). Infrared canopy temperature of early-ripening peach trees under postharvest deficit irrigation. Agricultural Water Management 97: 1787-1794. - doi: 10.1016/j. agwat.2010.06.014

Wilson KB, Hanson PJ, Mulholland P, Baldocchi DD, Wullschleger S (2001). A comparison of methods for determining forest evapotranspiration and its components: sap flow, soil water budget, eddy covariance and catchment water balance. Agricultural and Forest Meteorology
106: 153-168. - doi: 10.1016/S0168-1923(00)0019 9-4

You GY, Zhang YP, Liu YH, Schaefer DA, Gong HD, Gao JB, Lu ZY, Song QH, Zhao JB, Wu CS, Yu L, Xie TN (2013). Investigation of temperature and aridity at different elevations of $\mathrm{Mt}$. Ailao, SW China. International Journal of Biometeorology 57: 487-492. - doi: 10.1007/s004 84-012-0570-6

Zhang JL, Zhu JJ, Cao KF (2007). Seasonal variation in photosynthesis in six woody species with different leaf phenology in a valley savanna in southwestern China. Trees-structure and Function 21: 631-643. - doi: 10.1007/s00468007-0156-9

Zhang YJ, Holbrook NM, Cao KF (2014). Seasonal dynamics in photosynthesis of woody plants at the northern limit of Asian tropics: potential role of fog in maintaining tropical rainforests and agriculture in Southwest China. Tree Physiology 34 (10): 1069-1078. - doi: 10.1093/tree phys/tpuo83

Zhang Y, Meinzer FC, Qi JH, Goldstein G, Cao KF (2013). Midday stomatal conductance is more related to stem rather than leaf water status in subtropical deciduous and evergreen broadleaf trees. Plant Cell and Environment 36: 149-158. doi: 10.1111/j.1365-3040.2012.02563.x

\section{Supplementary Material}

Fig. S1 - Observational towers in the tropical rainforest (TRF), the subtropical evergreen forest (STF) and the savanna forest (SAF).

Fig. S2 - Mean diurnal time series of sap flow during dry and wet season at TRF and STF sites.

Fig. $\mathbf{3} 3$ - Mean diurnal time series of soil water content at TRF and STF sites.

Link: Song_2223@supplo01.pdf 